\title{
A CLINICAL TRIAL OF PENTA-ERYTHRITOL TETRANITRATE, A KHELLIN DERIVATIVE (RECORDIL), AND IPRONIAZID IN ANGINA OF EFFORT
}

\author{
BY \\ H. A. DEWAR, A. R. HORLER, AND D. J. NEWELL \\ From the Royal Victoria Infirmary and the Nuffield Department of Industrial Health, King's College, Newcastle upon Tyne
}

Received October 6, 1958

That there is room for improvement in the medicinal treatment of angina of effort, no one will dispute. The clinical trial to be described was designed to test the efficacy of a khellin derivative, iproniazid, and the already widely used penta-erythritol tetranitrate, in the relief of anginal pain.

THE DRUGS

Penta-erythritol tetranitrate (P.E.T.N.) has the chemical formula

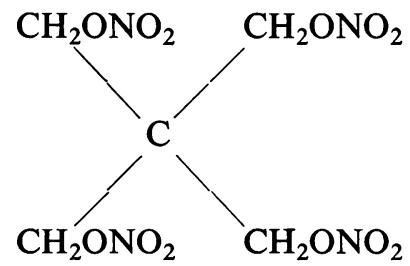

It was first introduced into medical practice in Sweden during the recent war, and has been subjected to a considerable number of clinical trials (Balatre et al., 1949; Winsor and Humphreys, 1952; Perlman, 1952; Plotz, 1952; Talley et al., 1952; Silber and Katz, 1953; Friedberg, 1953; Weitzman, 1953; Russek, et al., 1955; Winsor and Scott, 1955; Russek, et al, 1955; Rosenberg and Michelson, 1955; Cole et al., 1957; Fife et al., 1958; Riseman et al., 1958). Conclusions as to its efficacy have differed widely and this is no doubt largely due to the different criteria and techniques of investigation employed. In some of the recorded trials, the results have been based on exercise tolerance tests, and the cardiographic changes and the onset and severity of pain were taken as the criteria by which to compare the drug either with a placebo or with no treatment at all. In other trials, criteria included the patients' own impressions, and their records of attacks of pain and consumption of nitroglycerine tablets over a period of weeks. In general, the use of controls has not been uniform, nor has a "double-blind" technique been employed as a means of eliminating observer error. Where exercise tolerance tests were used, the results were largely favourable to the drug (Winsor and Humphreys, 1952; Weitzman, 1953; Russek et al., 1955; Winsor and Scott, 1955; Riseman et al., 1958), while in other trials, results were less encouraging, particularly where more stringent criteria and use of controls were employed. Weitzman (1953), whose use of controls did not include a "double-blind" technique, found "unquestionable and sustained improvement in onefifth of the patients tested," while Fife et al. (1958), employing a "double-blind" method, found the superiority of the drug to a placebo "at best marginal." Penta-erythritol tetranitrate is said to be more effective when given before, rather than after food, and in larger, rather than smaller dose, although side effects have been troublesome with the larger amounts (Russek et al., 1955). 
The khellin derivative, flavone-7-ethyl oxyacetate (recordil) was the most promising of a number of flavone compounds prepared by Dr. D. Recordati of Milan, and has the following structural formula:

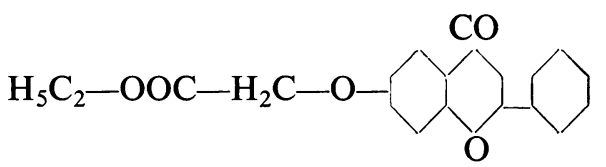

Giordano and Turrisi (1956) considered that it had a coronary vasodilator effect 14 times greater than khellin and equal to that of amyl nitrite. They concluded, in a clinical trial on 18 patients, that it abolished the angina in 9, improved it in 6, and had no effect in 3 . They also claimed that side effects were much fewer than with khellin. The trial was controlled by the use of a placebo, but full details of the design of the trial were not given. The dosage schedule employed was " one $15 \mathrm{mg}$. tablet a day, gradually increased over 7 to 8 days to 3 or 4 tablets daily ( 45 to $60 \mathrm{mg}$.), and given over a period of at least three months."

Iproniazid (1-isonicotinoyl-2-isopropyl hydrazine), a derivative of the antituberculous drug isoniazid, has similar antituberculous properties, but is also a potent inhibitor of amine oxidase. Its alleged value in the relief of angina is thought to stem either from its ability to prevent breakdown of adrenaline, nor-adrenaline, and serotonin (the "metabolic effect"-Cesarman, 1957) or from its ability to block the specific stimulus originating pain ("antalgic effect"). It is also thought to diminish the excitability or contractility of skeletal and cardiac muscle (Cossio, 1958). Beneficial side effects are said to be euphoria and increased appetite and weight. Toxic effects reported include muscle tremor, increased reflexes, constipation, dysuria, insomnia, dizziness, headache, orthostatic hypotension, peripheral neuritis, psychosis, jaundice, and intensification of pre-existing epilepsy. Cesarman (1957) reported complete relief of pain in 41 patients with angina of effort treated with this drug. No control with dummy tablets was done, the sole comparison being with periods when no drug was given. The dose used was $50 \mathrm{mg}$. three times daily, and the effect was manifest between the fourth and twelfth days. The electrocardiogram at rest and after standardized effort was said to show improvement. Cossio (1958) did use dummy tablets as well as iproniazid in a trial on 85 patients, but iproniazid was invariably given first and a "double-blind" technique was not employed. He found that one-third of the patients lost all or nearly all their pain usually within a week, and some improvement was experienced by a further third. The electrocardiographic test, however, remained positive even though pain might no longer occur.

\section{DESIGN OF THE TRIAL}

The form of this trial fell into three parts as a result of two additions to the original plan. Initially the intention was to compare the effects of the khellin derivative with penta-erythritol tetranitrate and with a dummy, and accordingly, the first part of the trial was designed to this end. Later, because of the uncertainty as to the optimum dose of penta-erythritol tetranitrate, it was decided to extend the trial to test the effect of P.E.T.N. in a higher dosage. While this part of the trial was actually in progress an offer was received for a supply of iproniazid and for this reason the investigation was again prolonged so that the same patients could be used to test the efficacy of this drug.

Comparison of Khellin Derivative, P.E.T.N., and Dummy. It was not expected or intended that the drugs used would have a permanent effect upon the patients' disease. The desired effect was the suppression of symptoms during the period of administration and it was thought likely that this effect would be short-lived. For this reason it was decided to administer the drugs consecutively to the same patients, and thus to eliminate the effect that the differences between individual patients, particularly differences in the severity of their angina, would have upon the results. It was possible, however, that the effect of a drug might persist for a period after its withdrawal, especially as it has been shown in previous trials (Evans and Hoyle, 1933; Weitzman, 1953; Cole et al., 1957) that any improvement that may occur, even with a dummy, is frequently maintained for some time after the 
drug has been discontinued. It had also to be considered that in such trials patients might respond well to the first administered drug, whatever it might be, and then, becoming accustomed to the routine, give a less favourable response to succeeding drugs. Because of these considerations, it was decided to employ a "cross-over" design originally used by Williams (1949) in nutrition studies on cows. The three basic requirements of such a design were: (1) each patient should receive each of the three agents (khellin derivative, P.E.T.N., and dummy); (2) during each treatment period the same number of patients should be receiving each of the agents and (3) a period of treatment with each agent should have been preceded by a period with each other agent and by itself an equal number of times.

There were six possible ways in which the three agents used for this part of the trial could be arranged in sequence. The design was such that each group of six patients should represent all these possible sequences. The particular sequence for each patient was determined from a prearranged list in which the sequences were arranged in random order within each group of six. The key to the order of tablets, which was unknown to the two physicians conducting the trial, was kept by the hospital pharmacist who entered each patient's name on the key as he was included in the trial.

"Treatment periods" consisted of a fortnight, but the first administered drug of any sequence was given for two "treatments periods," and the results of the second fortnight only were used in the analysis. In this way, data for comparison of the three agents were drawn from the results of the second fortnightly period on the first agent and the succeeding fortnightly periods on the second and third.

The three types of tablets used in this first part of the trial were not of identical appearance since the khellin derivative was only available in tablets bearing a brand mark. However, the P.E.T.N. was supplied without any distinguishing mark (so that it could not be identified with the commercial mycardol with which many of the patients were already familiar) and the dummy tablets were identical in appearance with the P.E.T.N.

The khellin derivative was administered in a dose of one 15-mg. tablet three times daily after meals. P.E.T.N. was given before meals in a dose of one $30-\mathrm{mg}$. tablet three times daily, and the dummy tablets, one three times daily after meals.

Extension of the Trial. As each patient completed the first part of the trial, he was given a further course of penta-erythritol tetranitrate in double the previous dose $(60 \mathrm{mg}$. three times daily before meals) over a period of a fortnight.

The introduction of iproniazid necessitated the employment of a separate design and control. Each patient was given this drug for three weeks and another dummy identical in appearance with it for another three weeks. The order in which they were given was again determined at random. The dose of iproniazid was one 50-mg. tablet three times daily, whenever it could be tolerated. In view of the possible side effects the patients were instructed to reduce the dose to two, or if necessary to one tablet daily if the drug upset them. In the event, 7 patients found it necessary to do this, and the dose taken in their case was the largest amount that could be tolerated short of $150 \mathrm{mg}$. daily. (It is characteristic of this kind of clinical trial that two patients found it necessary to reduce the dose of the dummy tablets, with regard to which similar instructions had been given.)

\section{Method of Conducting the Trial}

It was decided to use the "double-blind" method of trial employed by Greiner et al. (1950) and the patient's record card as modified by Lewis et al. (1956). Neither the patients nor the physicians knew during the trial which drug was being given at any particular time. The record card was divided into a series of squares; the vertical columns were marked with each day of the week and the transverse columns with a description of the day in respect of pain-" "same as usual," "less than usual (good day)," "more than usual (bad day)" and "no pain at all." The patient was required to enter on the card his own assessment of the efficacy of the drugs by placing a cross in the appropriate square each day, and in addition, to record daily the number of attacks of anginal pain he had 
experienced, and the number of nitroglycerine tablets he had found it necessary to take. In this way it was possible to estimate for each period of treatment, the number of days pain-free, good, bad, or the same, the total number of attacks of pain and the total number of nitroglycerine tablets taken.

At each attendance the patient was asked to give his own general opinion of the effect of the drug and to report any side effects. Twelve lead electrocardiograms were taken at each visit, and also in view of the alleged hypotensive effect of iproniazid (Cesarman, 1957) the blood pressure was recorded at each visit during the third part of the trial.

\section{Selection of Patients}

The patients invited to take part were typical cases of angina of effort due to presumed coronary atheroma. Care was taken to include only those in whom angina appeared to be in a stable state and who seemed capable of keeping a reliable record. As regular attendance as an outpatient was required, no patient with severe angina at rest or impending heart failure was included.

Twenty-four patients began the trial but only 19 completed the first part and provided records suitable for analysis. Two died during the course of the investigation, probably of myocardial infarction, and three others had to be withdrawn because of bad record-keeping. Another patient sustained a myocardial infarct just as his trial with iproniazid was beginning and therefore took no further part. Two new patients were added to the iproniazid section of the trial from which 20 record cards were therefore available for analysis. In all, there were 21 patients whose records were used for part or for all of the trial. Of these, 19 were men and 2 women. Their ages ranged from 37 to 70 years with a mean of 51 years. Seven patients, on their first attendance, had a diastolic blood pressure higher than $100 \mathrm{~mm}$. of mercury, and two of these were already receiving treatment with mecamylamine; this was continued in unchanging dosage. Two patients had cardiographic evidence of a previous myocardial infarct.

\section{RESULTS}

Effects of Khellin Derivative and Penta-erythritol Tetranitrate. As stated above, only 19 patients out of the original 24 completed the first part of the trial. In consequence, three of the groups of six mentioned in the design were incomplete. It would have been possible to substitute other patients and allot to them the necessary sequence of tablets to complete the groups of six; this was not done because the results from the 19 patients already available suggested that such a course was not worth while, and patients differed so much in their number of attacks of pain that the "carry-over" effect of a drug into the next period could not be calculated. In point of fact, with regard to the 19 patients whose records were available, each treatment had been preceded by each other treatment and itself approximately the same number of times, and the results for a particular agent were unlikely to have been biased by what had gone before.

The results of this part of the trial are summarized in Table I.

TABLE I

Results of Comparison of Khellin Derivative, P.E.T.N., and Dummy

\begin{tabular}{|c|c|c|c|c|c|c|}
\hline \multirow[b]{2}{*}{ Tablets administered } & \multicolumn{4}{|c|}{ Average number of days } & \multirow[b]{2}{*}{$\begin{array}{l}\text { Average No. of } \\
\text { attacks of pain }\end{array}$} & \multirow{2}{*}{$\begin{array}{c}\text { Average No. of } \\
\text { nitro-glycerine } \\
\text { tablets }\end{array}$} \\
\hline & Pain-free & With less pain & Unchanged & $\begin{array}{l}\text { With more } \\
\text { pain }\end{array}$ & & \\
\hline $\begin{array}{l}\text { Khellin derivative . } \\
\text { P.E.T.N. } 30 \mathrm{mg} \text {. t.i.d. } \\
\text { Dummy tablets } \\
\text { P.E.T.N. } 60 \mathrm{mg} \text {. t.i.d. }\end{array}$ & $\begin{array}{l}3 \cdot 5 \\
2 \cdot 7 \\
4 \cdot 6 \\
3 \cdot 6\end{array}$ & $\begin{array}{l}5 \cdot 4 \\
6 \cdot 4 \\
4 \cdot 6 \\
5 \cdot 4\end{array}$ & $\begin{array}{l}4 \\
3 \cdot 6 \\
3 \cdot 9 \\
3 \cdot 1\end{array}$ & $\begin{array}{l}1 \cdot 2 \\
1 \cdot 3 \\
0 \cdot 8 \\
1 \cdot 8\end{array}$ & $\begin{array}{l}24 \\
22 \\
23 \\
22\end{array}$ & $\begin{array}{l}23 \cdot 6 \\
20 \cdot 6 \\
21 \cdot 7 \\
21\end{array}$ \\
\hline
\end{tabular}


(a) Number of Attacks of Pain. There was no significant difference between the effect of the khellin derivative, P.E.T.N., and the dummy; the average number of attacks in a fortnight was, with the khellin derivative 24, with P.E.T.N. 22, and with the dummy 23. A separate analysis revealed that there was likewise no significant difference between the attacks of pain experienced by all the patients in each of the three consecutive treatment periods, irrespective of which tablets were being taken. The average numbers of attacks in the three fortnightly periods were respectively 23,24 , and 22. These are so close that they cannot have influenced the treatment comparisons. Differences between individual patients were very great, ranging from two patients with one and ten attacks in six weeks and two others with 168 and 306.

(b) Assessment of Each Day in Respect of Pain. There was no significant difference between the effect of the three substances on the number of days with more pain, on the number of days with less pain, or on the number of days in which the pain was unchanged. Again, for these criteria the fortnightly periods did not differ significantly from each other, although individual patients differed greatly.

The average number of pain-free days was with khellin derivative $3 \cdot 5$, with P.E.T.N. $2 \cdot 7$, and with dummy 4.6. This difference is significant $(P<0.05)$. While one result out of a number of similar analyses being significant at the 5 per cent level is not uncommon, even with all drugs equally effective, it is interesting to note that the agent producing the greatest number of pain-free days was the dummy.

(c) Number of Nitroglycerine Tablets Consumed. This criterion, which is probably less important than the others, also disclosed no difference between the effect of the two drugs and the dummy. The number of nitroglycerine tablets taken was understandably closely related to the number of attacks of pain.

Effect of Penta-erythritol Tetranitrate in Higher Dosage. When the trial was extended to include a further period on the double dose of P.E.T.N. there was no significant difference by any of the criteria, between the results of this treatment and of those previously given (see Table I). The average number of attacks of pain in the fortnight was 22 , the same as with the smaller dosage, and there was similarly no significant difference in the number of nitroglycerine tablets consumed. The average number of pain-free days was $3 \cdot 6$, the same figure as the average of the results from the three previous treatments.

Effect of Iproniazid. As explained earlier, this part of the trial was conducted on 18 patients from the previous part and 2 additional ones, and the order of administration of drug and dummy was determined by a random method. Of the 20 patients, 11 received the dummy for the first three weeks and 9 the iproniazid. The results are summarized in Table II.

TABLE II

RESUltS OF COMPARISON OF IPRONIAZID AND DUMMY

\begin{tabular}{|c|c|c|c|c|c|c|}
\hline \multirow[b]{2}{*}{ Tablets administered } & \multicolumn{4}{|c|}{ Average number of days } & \multirow[b]{2}{*}{$\begin{array}{l}\text { Average No. of } \\
\text { attacks of pain }\end{array}$} & \multirow{2}{*}{$\begin{array}{c}\text { Average No. of } \\
\text { nitro-glycerine } \\
\text { tablets }\end{array}$} \\
\hline & Pain-free & $\begin{array}{l}\text { With less } \\
\text { pain }\end{array}$ & Unchanged & $\begin{array}{l}\text { With more } \\
\text { pain }\end{array}$ & & \\
\hline $\begin{array}{lll}\text { Iproniazid } & \ldots & \ldots \\
\text { Dummy } & \ldots & \ldots\end{array}$ & $\begin{array}{c}7 \cdot 2 \\
(2 \cdot 5) \\
8 \cdot 4 \\
(2 \cdot 4)\end{array}$ & $\begin{array}{c}6 \cdot 9 \\
(2 \cdot 6) \\
7 \cdot 6 \\
(3 \cdot 4)\end{array}$ & $\begin{array}{l}4 \cdot 6 \\
(1) \\
3 \cdot 5 \\
(1 \cdot 1)\end{array}$ & $\begin{array}{c}1 \cdot 7 \\
(0 \cdot 5) \\
1 \cdot 5 \\
(0 \cdot 2)\end{array}$ & $\begin{array}{c}28 \\
(7 \cdot 8) \\
22 \\
(7 \cdot 8)\end{array}$ & $\begin{array}{l}26 \cdot 4 \\
(7 \cdot 8) \\
21.5 \\
(7 \cdot 1)\end{array}$ \\
\hline
\end{tabular}

Treatment period 21 days (figures in brackets are the results from the last 7 days of each treatment period). Number of patients 20.

The average number of attacks of pain in the 3-weekly periods was for iproniazid 28, and for dummy 22. These figures are not significantly different. There was also no significant difference between the two substances with regard to any of the other criteria. 
It was also considered that owing to the delayed development of action of iproniazid (Cesarman, 1957) and to a possible prolongation of this action after withdrawal of the drug, valid comparison between drug and dummy might only be obtained during the third week of each period. Because of that a separate analysis was made of the results of the third week of each treatment period. The average number of attacks of pain for both iproniazid and dummy was the same-7.8 -and the other criteria likewise demonstrated no significant difference.

The average numbers of attacks of pain sustained by all the patients in the first and second 3-week periods were 28 and 22 respectively, and in the last week of the two periods, 7.9 and 7.6 respectively. Neither difference is significant. As the dummy was administered to more patients in the first period, these differences can have no bearing on the slightly greater number of attacks of pain experienced with iproniazid.

\section{The PATIENTS' ImPressions OF Treatment}

The patients' own impressions as to the efficacy of the different tablets were rather difficult to evaluate. The more intelligent patients assessed the effect of the treatments relative to the whole series, whereas others were apt to compare a particular treatment with that which had immediately preceded it. Statements of improvement or deterioration, therefore, needed to be qualified.

During the first part of the trial and the extra period on the higher dosage of P.E.T.N., the patients assessed their progress as shown below.

\section{Drug}

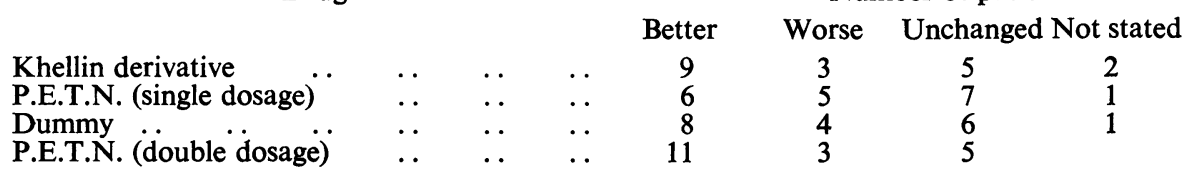

The general trend would seem to indicate a slight preference for pentaerythritol tetranitrate in the higher dosage, but this could easily be attributed to chance.

In the second part of the trial, the results again based on the patients' own assessments, were virtually identical as regards iproniazid and the dummy tablets.

$\begin{array}{llllccc} & & & & \text { Better } & \text { Worse } & \text { Unchanged } \\ \text { Iproniazid } & . & \ldots & . . & 14 & 4 & 2 \\ \text { Dummy } & . & \ldots & . . & 14 & 5 & 1\end{array}$

\section{SIDE EFFECTS}

Khellin Derivative. Twelve of the 19 patients who received this drug did not complain of any side effects. Two complained of dizziness, one of whom also had nausea, and the remainder complained respectively of a warm glow in the mouth, heaviness in the arms, hot flushes, headache, and dryness of the skin.

P.E.T.N. Penta-erythritol tetranitrate in single dosage produced no side effects in 9 patients. Three complained of nausea and gastric discomfort, and the various complaints of the remainder included palpitation, headache, dizziness, blurring of vision, substernal discomfort (after the tablets), salivation and waterbrash, and constipation. Each of these latter symptoms was experienced by one patient only. When taken in double the dosage P.E.T.N. produced headache in 7 patients, 2 of whom also complained of nausea. Further side effects on this dosage were palpitation, gastric discomfort, dizziness, tiredness of the legs, eructations of wind, vomiting, and sweating. Seven patients experienced no side effects.

Iproniazid. Of 20 patients receiving this drug, 5 complained of constipation and 4 of headache. One complained of a recurrence of epileptic fits, and another of a feeling of euphoria, "as though I had just had three gins." Other complaints included pruritus, nausea, a burning sensation in the hands, vertigo, and mental dullness. Several of these symptoms might be complained of by the 
same patient. Only 5 had no side effects from iproniazid. In 6 patients there was a fall in systolic blood pressure of over $20 \mathrm{~mm}$. $\mathrm{Hg}$ after the period on iproniazid. One of these was also receiving mecamylamine and another was suspected of having a myocardial infarct.

Dummy. Side effects were also produced by the placebo tablets. In the first part of the trial 14 out of 19 patients found no adverse effects from the dummy tablets. The remainder complained of drowsiness, flushing, aching in the spine, nausea, and slight looseness of the bowels. During the later part of the trial, only 10 out of 20 patients experienced no side effects with the dummy tablets. Five complained of constipation, 2 of headache, and 2 of blurred vision; other complaints were nausea, tiredness, abdominal pain, and dizziness.

\section{Discussion}

Cole et al. (1957) have stated that when patients with angina are introduced into a clinical trial in which they have to make a daily record of the number of attacks of pain that they sustain, such a record will, in 50 per cent of instances and quite regardless of the order of the treatment, resemble a ski slope. This is defined as "an initial downward slope of decreased frequency of attacks, representing improvement during the first 11 weeks on the average, followed by a long plateau that usually remained at this lower level of pain frequency. The initial period of improvement is attributed to the psychotherapeutic effect of increased attention and solicitous care inherent in a research program as compared with routine clinical care." The trial here described, by mixing drugs and dummies sufficiently, was designed to prevent such a ski slope from affecting the results. In the event the ski slope did not appear and only in the last period, when iproniazid and dummy were being given, was there a significant reduction in the incidence of attacks of pain; the incidence was greatly influenced by three rather severe cases. An improvement in the weather is as likely a cause for this as "increased attention or solicitous care" and the results are not affected by it. The portion of the trial in which a double dosage of P.E.T.N. was added, is open to valid criticism in that it is not possible to decide unequivocally whether the results in this period are solely the effects of the treatment or are possibly influenced by some other factor such as the psychological (depressing?) effects of continuing the trial. For this reason the results from this part of the trial should perhaps be interpreted with caution.

It would not be fair, however, to conclude from this trial that the drugs tested are entirely without influence on the coronary blood flow of patients with angina. The S-T changes produced by exercise in the electrocardigoram of such patients constitute a more objective criterion of adequacy of blood flow, and drugs with a good theoretical basis for being effective should not be wholly rejected until their influence upon such exercise tests has been evaluated. It is unfortunate that it is so difficult to arrange such tests in a safe and acceptable manner with all variables eliminated, including especially the instability of the disease process itself. The feature of coronary insufficiency that goes by the name of angina is, however, a subjective sensation and under the conditions of this trial none of the drugs tested has ameliorated it significantly.

\section{SUMmaRY}

In a controlled "double-blind" clinical trial, a khellin derivative, penta-erythritol tetranitrate, and iproniazid were compared with dummy tablets for their effect upon angina.

In the doses used no significant differences were found between the effects of these drugs and dummy tablets.

Penta-erythritol tetranitrate was tried also in a double dose (180 mg. daily) but without significant improvement.

The side effects produced by these drugs are described.

Our thanks are due to Bayer Products Limited for supplies of P.E.T.N. (mycardol) and dummy tablets, to Dr. D. Recordati of Milan for the khellin derivative, to Roche Products Limited for the iproniazid (marsilid) and dummy tablets, and to Miss Garnett and her staff of the Pharmacy Department, Royal Victoria Infirmary, for very helpful co-operation in the clinical trial. 


\section{REFERENCES}

Balatre, P., Merlen, J-F., and Grandjean, L. (1949). Presse méd., 57, 1067.

Cesarman, T. (1957). Arch. Inst. Cardiol. Mex., 27, 563.

Cole, S. L., Kaye, H., and Griffith, G. C. (1957). Circulation, 15, 405.

Cossio, P. (1958). Amer. Heart J., 56, 113.

Evans, W., and Hoyle, C. (1933). Quart. J. Med., 2, 311.

Fife, R., Hewitt, G., and Stevenson, J. (1958). Scot. med. J., 3, 15.

Friedberg, C. K., (1953). Canad. med. Ass. J., 68, 95.

Giordano, G., and Turrisi, E., (1956). Clin. Terap., 10, 670.

Greiner, T., Gold, H., Cattell, M., Travell, J., Bakst, H., Rinzler, S. H., Benjamin, Z. H., Warshaw, L. J., Bobb, A. L., Kwit, N. T., Modell, W., Rothendler, H. H., Messeloff, C. R., and Kramer, M. L. (1950). Amer. J. Med., 9, 143.

Lewis, B. I., Lubin, R. I., January, L. E., and Wild, J. B. (1956). Circulation, 14, 227.

Perlman, A. (1952). Angiology, 3, 16.

Plotz, M. (1952). New York St. J. Med., 52, 2012.

Riseman, J. E. F., Altman, G. E., and Koretsky, S. (1958). Circulation, 17, 22.

Rosenberg, H. N., and Michelson, A. L. (1955). Amer. J. med. Sci., 230, 254.

Russek, H. I., Zohman, B. L., and Dorset, V. J. (1955). Amer. J. med. Sci., 229, 46.

- - Drumm, A. E., Weingarten, W., and Dorset, V. J. (1955). Circulation, 12, 169.

Silber, E. N., and Katz, L. N. (1953). J. Amer. med. Ass., 153, 1075.

Talley, R. W., Beard, O. W., and Doherty, J. E. (1952). Amer. Heart J., 44, 866.

Weitzman, D. (1953). Brit. med. J., 2, 1409.

Williams, E. J. (1949). Aust. J. Sci. Res., A2, 169.

Winsor, T., and Humphreys, P. (1952). Angiology, 3, 1.

$\longrightarrow$, and Scott, C. C. (1955). Amer. Heart J., 49, 414. 